\title{
REPRESENTASI CITRA PEREMPUAN DALAM IKLAN VITAGLOW FAIR\&LOVELY
}

\author{
Heri Setiawan, Yusuf Sapari, Ahmad Yusron, Dea Angkasa Putri Supardi \\ Email: setiawanheri614@gmail.com,ysapari73@gmail.com, Ahmad.yusron@umc.ac.id \\ Program Studi Ilmu Komunikasi \\ Universitas Muhammadiyah Cirebon
}

\author{
Submitted: 29 Juni 2020| Accepted: 24 September 2020 | Published: 30 \\ Desember 2020 \\ Website: https://e-journal.umc.ac.id/index.php/jike/index
}

\begin{abstract}
The development of the times that makes today's society oriented to only one dimension, namely capitalism. Then from this incident was born a new culture of consumerism. In fact, many unknown ideologies have occurred without us realizing it in the environment around us. This study discusses the meaning in the Vitaglow Fair\&Lovely mask advertisement which aims to find out what meaning is contained in the advertisement. In this advertisement, John Fiske's Semiotics research method is used, in which there are three levels, namely the level of reality, the level of representation and the level of ideology. The purpose of this study is to find the meaning in the advertisement with three levels, namely the level of reality, representation and ideology. The results of John Fiske's semiotic analysis in VitaGlow Fair \& Lovely advertisements, Vitaglow Fair \& Lovely advertisements classify 3 images out of 5 existing images, namely Citra Pigura depicting women as formed creatures. The woman in the advertisement is described as having whiter, smoother, and brighter skin after using the VitaGlow sheet mask. The writer's analysis of Vitaglows Fair \& Lovely as a whole shows that women must always look good, but remain confident and rise to face problems. The ideological level analysis in the Vitaglows Fair \& Lovely video ad depicts femininity which really represents pure women who are cheerful, fun, cares about themselves and cares for other women. The ideology of consumerism represents the message of capitalism where the three advertisements have motivated women not to feel inferior and dare to change their appearance but still lead the dream to change their appearance and make profits.
\end{abstract}

Keywords: level of reality, level of representation, level of ideology, consumerism

\begin{abstract}
ABSTRAK
Perkembangan zaman yang membuat masyarakat saat ini berkiblat hanya pada satu dimensi saja yaitu kapitalisme. Kemudian dari kejadian ini lahirlah suatu budaya baru yang dinamakan budaya konsumerisme. Sebenarnya ideology tersebut banyak tidak diketahui telah terjadi tanpa kita sadari dalam lingkungan sekitar kita. Penelitian ini membahas tentang pemaknaan dalam iklan masker Vitaglow Fair\&Lovely yang bertujuan untuk mengetahui makna apa yang terdapat dalam iklan tersebut. Dalam iklan ini menggunakan metode penelitian Semiotika John Fiske yang mana terdapat tiga level yaitu level realitas, level representasi dan level ideology. Tujuan penelitian ini mencari makna yang ada didalam iklan tersebut dengan tiga level tadi yaitu level realitas, representasi dan ideology. Hasil analisis semiotika John Fiske dalam iklan VitaGlow Fair \& Lovely maka yaitu iklan Vitaglow fair\&lovely dikategorikan 3 citra dari 5 citra yang ada yaitu Citra Pigura menggambarkan perempuan sebagai makhluk yang memikat. Perempuan dalam iklan tersebut digambarkan memikat, kulit lebih putih, halus, dan cerah setelah menggunakan VitaGlow sheet mask. Analisis penulis menyimpulkan iklan Vitaglows Fair \& Lovely secara keseluruhan bahwa perempuan harus selalu tampil memikat, merawat diri, namun tetap percaya diri dan bangkit menjadi perempuan cantik walaupun menghadapi masalah. Analisis level ideologi pada iklan video Vitaglows Fair \& Lovely menggambarkan feminitas yang benar-benar mempresentasikan pure perempuan yang ceria, fun, peduli merawat diri dan peduli akan sesama perempuan. Ideologi konsumerisme iklan tsb merepresentasikan pesan kapitalisme dimana ketiga talent telah memotivasi perempuan-perempuan untuk tidak merasa rendah diri dan berani berubah dalam penampilan mereka namun tetap menggiring impian untuk mengubah tampilan dan meraih keuntungan.
\end{abstract}

Kata kunci : level realitas, level representasi, level ideology, konsumerisme 


\section{A. PENDAhULUAN}

Posisi perempuan di tengah masyarakat tidaklah menguntungkan di sisi lain dimana masyarakat seolah mewajibkan perempuan untuk memenuhi standar soal kecantikan, penampilan, dan perilaku yang berlaku. Bagi mereka, perempuan yang memiliki nilai guna dan nilai tukar adalah yang memenuhi memenuhi standar yang berlaku di masyarakat.

Sisi lain, perempuan sebagai komoditas dalam iklan produk seringkali dipakai sebagai model. Media massa telah mengunakan perempuan sebagai model komoditas produk yang layak dipromosikan ke masyarakat umum. Seperti diungkap oleh Fernandez (2013) bahwa perempuan dengan daya tarik seksualnya menjadi salah satu senjata andalan iklan untuk menarik perhatian target komunikasinya. Perempuan dianggap lebih efektif dalam upaya merebut perhatian dari khalayak sasaran (Fithyarini, 2013; Susilo, 2017).

Jagad periklanan baik melalui media cetak, media elektronik, maupun media luar selalu dimarakkan oleh kaum hawa sebagai model iklan. Kecantikan dan keindahan yang ditampilkan oleh perempuan digambarkan sebagai alat untuk menarik perhatian kaum lakilaki. Kecantikan dan keindahan ini mencakup wajah yang menawan, tubuh ramping, tinggi, dan terlihat muda (Kumalaningtyas \& Sadasri, 2018). Di samping itu keindahan dan kecantikan perempuan terlihat pada kulit putih dengan rambut panjang, hitam dan lurus.

Kegiatan periklanan yang menggunakan objek atau komoditas perempuan bukanlah hal yang tabu atau dilarang bahkan menjadi sesuatu yang lumrah dilakukan oleh produsen produk kecantikan. Kegiatan iklan dengan menggunakan objek perempuan sebagai model iklan telah diteliti dan dijadikan kajian khusus sehingga lahirlah istilah femvertising. Praktik femvertising (female empowerment advertising) tidak lantas membebaskan perempuan dari posisi sebagai objek atau komoditas dalam peta periklanan di Indonesia.

Femvertising muncul pada periode 2000-an sebagai bentuk respons terhadap commodity feminism yang menguasai pasar selama hampir 3 dekade. Samantha Skey sebagaimana dikutip oleh Becker-Herby (dalam Kumalaningtyas dan Sadasri, 2018) memperkenalkan istilah femvertising sebagai iklan yang menampilkan talent, pesan, dan citra yang mendukung perempuan dan memberdayakan perempuan. Femvertising membawa perempuan ke garda depan dan menyamaratakan representasi perempuan dalam perbandingannya dengan laki-laki dalam dunia iklan.

Konsep femvertising ini juga tampak dipakai pada iklan Vitaglows fair\&lovely. Iklan ini seolah mempromosikan kecantikan perempuan yang beragam, tidak hanya harus memiliki 
tubuh yang ramping dan sexy, rambut hitam semerbak wangi tapi juga memiliki kulit putih mulus. Kendati demikian, iklan ini tetap menetapkan syarat soal kulit sebagai standar kecantikan perempuan, yakni asalkan kulitnya cerah dan mulus.

Dari uraian diatas maka penulis tertarik untuk menganalisis video iklan Vitaglows Fair \& Lovely sebagai kajian utama penelitian ini dalam analisis semiotika dari konsep John Fiske. Iklan Vitaglows Fair \& Lovely ini banyak mengandung makna yang bisa diteliti dan dianalisis sehingga bisa menggambarkan makna yang tersirat dari iklan tsb dan bisa dipahami oleh masyarakat.

Adapun fokus kajian dari penelitian dibatasi pada analisis level realitas, level representasi dan level ideologi dari konsep semiotika John Fiske.

\section{B. KAJIAN LITERATUR}

\section{Femvertising}

Femvertising atau female empowerment advertising merupakan istilah yang digunakan dalam sebuah strategi komunikasi dan pemasaran yang digunakan oleh sebuah brand untuk menginspirasi dan memberdayakan perempuan melalui pesan-pesan membangun (BeckerHerby, 2016). Istilah ini pertama muncul ke permukaan di tahun 2014, meski di tahun sebelumnya beberapa brand telah menggunakan konsep iklan yang serupa. Saat ini femvertising telah menjadi konsep yang populer dan menjadi magnet tersendiri dalam industri periklanan.

Penggambaran perempuan yang lebih dekat kepada khalayak dengan memasukkan lebih banyak pesan positif yang mendukung perempuan seperti lima pilar unit analisis di bawah ini yaitu :

\section{Utilization of diverse female talent}

Konsep ini dimaknai sebagai penggunaan beragam jenis talent iklan. Hal ini sejalan dengan esensi femvertising yang mengerti bahwa setiap perempuan lebih suka jika direfleksikan oleh model dengan ras, bentuk tubuh, dan usia seperti mereka (audiens) (Becker-Herby, 2016).

\section{Messaging that it inherently pro-female}

Pesan utama yang ingin disampaikan melalui femvertising adalah pemberdayaan, inspirasional dan inklusif (Becker-Herby, 2016). Pesan ini mencoba memunculkan sikap afirmasi, kepercayaan diri dan memotivasi, serta bukan menimbulkan kesan 
bahwa produk yang ditawarkan menjadi kunci untuk memperbaiki kekurangan fisik audiens.

\section{Pushing gender-norms boundaries}

Iklan kampanye femvertising memperlihatkan perempuan pada skenario dengan lanskap yang netral diluar stereotip tradisional atas gender perempuan (Becker-Herby, 2016). Kampanye femvertising jarang sekali menunjukkan wanita dengan pekerjaan domestic atau tugas lain yang berkaitan dengan pernikahan atau motherhood.

\section{Downplaying of sexuality}

Femvertising tidak sepenuhnya menghapus aspek seksualitas, melainkan menggeser cara menampilkannya pada audiens. Aspek seksualitas seperti kulit atau tubuh perempuan ditampilkan secara relevan dan autentik (misalnya atlet perempuan yang sedang berlatih dalam balutan sport bra bukan mengekspos belahan dada) (BeckerHerby, 2016).

\section{Ideologi Konsumerisme}

Dalam Kamus Besar Bahasa Indonesia konsumsi didefinisikan sebagai "pemakaian barang hasil produksi" (www.kbbi.web.id). Sebagai sebuah usaha menghabiskan nilai guna barang dan jasa, konsumsi adalah sebuah tindakan.

Tumbuhnya produktivitas telah mendorong peningkatan kemakmuran yang bermuara pada semakin mudahnya mayoritas penduduk mengakses beragam komoditi. Beraneka barang tersedia di pasar mulai dari produk industri makanan dan minuman, tekstil, elektronik, hingga otomotif, bahkan transaksi dapat dilakukan dengan hanya duduk menggenggam gadget. Kiranya tidak berlebihan mengatakan bahwa peningkatan kemakmuran berbanding lurus dengan peningkatan konsumsi. Perkembangan masyarakat kapitalis mendorong sosiolog seperti Storey (2017) mencari jawaban atas pertanyaan: "mengapa manusia tampaknya begitu banyak mengonsumsi dalam masyarakat kapitalis?”( Bakti, 2019).

Pertanyaan ini penting untuk diselami karena mengajak kita masuk ke dalam ranah pembahasan konsumerisme yang jauh lebih luas dan refleksif daripada istilah konsumsi. Konsumerisme adalah "atribut masyarakat" (Bauman, 2007 dalam Bakti, 2019), lebih dari sebuah tindakan mengonsumsi barang dan jasa, bahkan sering kali tindakan konsumsi yang dilakukan tidak dimaksudkan untuk memenuhi kebutuhan (Lodziak, 2002 dalam Bakti, 2019). Hal ini karena konsumerisme sudah menjadi "cara hidup" atau the way of life (Miles, 
2006). Esensi konsumerisme adalah sebuah prinsip bahwa konsumsi sebagai tujuan itu sendiri dan memiliki pembenarannya sendiri (Dunn, 2008 dalam Bakti, 2019).

Internalisasi struktur konsumerisme dapat menjelma menjadi habitus atau kesadaran praktis dalam diri seseorang (Nirzalin, 2013) yang dimanifestasikan melalui kegiatan belanja dan gaya hidup konsumtif. Tindakan sosial ini lahir secara refleks saja, kebanyakan minus refleksi.

\section{Iklan secara Umum}

Istilah advertising (periklanan) berasal dari kata Latin abad pertengahan advertere, "mengarahkan perhatian kepada". Istilah ini menggambarkan tipe atau bentuk pengumuman publik apa pun yang dimaksudkan untuk mempromosikan penjualan komoditas atau jasa, untuk menyebarkan sebuah pesan sosial atau politik. Sedangkan definisi iklan secara sederhana yakni pesan yang menawarkan suatu produk untuk ditujukan kepada masyarakt lewat suatu media. Dengan demikian, periklanan dapat diartikan sebagai taktik untuk memikat audience melalui berbagai strategi, serta mengevaluasinya, sehingga dapat menganalisis efektifitas komunikasi antara source dan decoder.

Dalam perspektif komunikasi cenderung menekankan sebagai proses penyampaian pesan dari komunikator kepada komunikan. Dalam perspektif iklan cenderung menekankan pada aspek penyampaian pesan yang kreatif dan persuasive yang disampaikan melalui media khusus. Perspektif pemasaran lebih menekankan pemaknaan iklan sebagai alat pemasaran yaitu menjual produk. Sementara dalam perspektif psikologi lebih menekankan aspek persuasif pesan.

Iklan (advertisement) adalah produk yang dihasilkan dari kegiatan beriklan (periklanan atau advertising). Jadi, iklan adalah produknya (barangnya, pesannya, bendanya). Sementara itu, iklan adalah segala bentuk pesan tentang suatu produk yang disampaikan melalui suatu media, dibiayai oleh pemrakarsa yang dikenal, serta ditujukan kepada sebagian atau seluruh masyarakat. Periklanan merupakan bentuk komunikasi massa, komunikasi yang dilakukan oleh pengiklan (advertiser) untuk mengkomunikasikan sesuatu kepada konsumen (decoder) melalui channel (media).

Iklan sebagai sebuah teks adalah sistem tanda yang terorganisir menurut kode-kode yang merefleksikan nilai-nilai tertentu, sikap dan juga keyakinan tertentu. Setiap pesan dalam iklan memiliki dua makna yang dikemukakan secara eksplisit dipermukaan makna yang dikemukakan secara implisit di balik permukaan tampilan iklan. Dengan demikian, 
semiotika menjadi metode yang sesuai untuk mengetahui konstruksi makna yang terjadi di dalam iklan. Karena semiotika menekankan peran sistem tanda dalam konstruksi realitas, maka melalui semiotika ideologi-ideologi yang ada di balik iklan bisa dibongkar.

\section{Jenis-jenis iklan}

Iklan dapat dibedakan berdasarkan beberapa hal, dalam pembelajaran ini disajikan jenis iklan berdasarkan media yang digunakan dan tujuan iklan. Berdasarkan jenis media yang digunakan, iklan dapat digolongkan sebagai berikut :

1. Iklan cetak

Iklan cetak adalah jenis iklan yang dipublikasikan menggunakan media cetak seperti koran, majalah, tabloid, dan lain-lain. Berdasarkan ruang yang digunakan dalam media surat kabar, majalah,tabloid, iklan dikenal dalam 2 bentuk yaitu :

a. Iklan baris adalah iklan yang hanya dibuat dalam beberapa baris, umumnya terdiri atas 3-4 baris dengan luas tidak lebih dari satu kolom. Biayanya reletif lebih murah, dihitung perbaris. Untuk menghemat biaya dan semua informasi dapat tersampaikan, bahasa yang digunakan dalam iklan ini umumya disingkat, penuh makna, dan sederhana. Hal yang diiklankan dalam iklan baris biasanya iklan lowongan pekerjaan, barang, jasa, dan lain-lain.

b. Iklan kolom adalah iklan yang dibuat dalam bentuk kolom. Iklan ini lebih tinggi dari pada iklan baris. Terkadang iklan ini juga dilengkapi dengan gambar, simbol, atau lambang yang mendukung isi iklan. Hal yang diiklankan berupa iklan barang dan jasa, loker dan lain-lain.

2. Iklan advertorial adalah jenis iklan yang dikemas seperti berita.

3. Iklan display, Dilihat dari bentuk, iklan display lebih besar dari pada iklan kolom.

Dalam iklan ini, ditampilkan gambar dan tulisan yang lebih besar

4. Iklan elektronik adalah iklan yang dipublikasikan dalam media elektronik.

\section{Semiotika}

Secara etimoligis istilah semiotik diambil dari kata Yunani seimeion yang berarti "tanda". Tanda itu sendiri didefinisikan sebagai sesuatu yang atas dasar konvensi sosial yang terbangun sebelumnya, dapat dianggap mewakili sesuatu yang lain. Pusat konsentrasi semiotika adalah kajian mengenai tanda dan cara tanda-tanda tersebut bekerja dan menciptakan makna. Sebuah tanda adalah sesuatu yang bersifat fisik, dapat diterima oleh 
indera; mengacu pada sesuatu diluar dirinya; dan bergantung pada pengenalan dari para pengguna bahwa itu adalah tanda.

Semiotik sendiri secara sederhana didefinisikan sebagai teori tentang tanda atau sistem tanda. Sedangkan tanda atau sign adalah sesuatu yang memiliki makna, yang mengkomunikasikan pesan-pesan kepada seseorang. Oleh karena itu, segala sesuatu bisa menjadi sebuah tanda misalnya buku, film, orang, bangunan dan juga iklan. Sebuah tanda (sign) dalam sitem makna dipisahkan ke dalam 2 komponen yaitu signifier (penanda) dan signified (petanda). Signifier adalah materi yang membawa makna sedangkan signified adalah maknanya. Signifier menunjukan pada dimensi konkret pada tanda. Sedangkan signified merupakan sisi abstrak tanda, makna yang dilekatkan pada tanda.

Semiotika merupakan ilmu yang mempelajari tentang tanda. Konsep tanda ini melihat bahwa makna muncul ketika ada hubungan yang bersifat asosiasi antara yang ditandai (signified) dan yang menandai (signifier). Tanda adalah kesatuan dari suatu bentuk penanda (signifier) dengan sebuah ide atau petanda (signified). Dengan kata lain, penanda adalah "bunyi yang bermakna" atau "coretan yang bermakna.

Semiotika adalah ilmu yang mempelajari tentang tanda (sign), fungsi tanda, penggunaan tanda dan segala sesuatu yang bertalian dengan tanda. Dengan kata lain, pengertian semiotik (tanda, pemaknaan, denotatum dan interpretan) dapat diterapkan pada semua bidang kehidupan asalkan ada persyaratan yang dipenuhi, yaitu ada arti yang diberikan, ada pemaknaan dan ada interpretasi.

Semiotik sebagai suatu model dari ilmu pengetahuan sosial memahami dunia sebagai sistem hubungan yang memiliki unit dasar yang disebut dengan 'tanda'. Dengan demikian semiotik mempelajari hakikat tentang keberadaan suatu tanda. Umberto Eco menyebut tanda tersebut sebagai "kebohongan", dalam tanda ada sesuatu yang tersembunyi dibaliknya dan bukan merupakan tanda itu sendiri.

Menurut Saussure, persepsi da pandangan kita tentang realitas, dikontruksikan oleh katakata dan tanda-tanda lain yang di gunakan dalam konteks sosial. Hal ini diangga sebagai pendapat yang sangat mengejutkan dan dianggap revolusioner, karena hal itu berarti tanda membentuj persepsi manusia, lebih sekedar merefleksikan realitas yang ada (Bignell, 1997 dalam Listiorini, 1999).

Secara etimologis, istilah semiotik berasal dari kata Yunani semeion yang berarti "tanda". Tanda itu sendiri didefinisikan sebagai sesuatu yang atas dasar konvensi sosial yang terbangun sebelumnya, dapat dianggap mewakili sesuatu yang lain. Istilah semeion 
tampaknya diturunkan dari kedokteran hipokratik atau asklepiadik dengan perhatiannya pada simtomatologi dan diagnostik inferensial. "Tanda" pada masa itu masih bermakna sesuatu hal yang menunjuk pada adanya hal lain.

Secara terminologis, semiotik dapat didefinisikan sebagai ilmu yang mempelajari sederetan luas objek-objek, peristiwa-peristiwa, seluruh kebudayaan sebagai tanda. Van Zoest (1996) mengartikan semiotic sebagai "ilmu tanda (sign) dan segala yang berhubungan dengannya: cara berfungsinya, hubungannya dengan kata lain, pengirimannya dan penerimaan nya oleh mereka yang mempergunakannya"

Sementara, istilah semiotika atau semiotik, yang dimunculkan pada akhir abad ke-19 oleh filsuf aliran pragmatik Amerika, Charles Sanders Peirce, merujuk kepada "doktrin formal tentang tanda-tanda”. Yang menjadi dasar semiotika adalah konsep tentang tanda: tak hanya bahasa dan sistem komunikasi yang tersusun oleh tanda-tanda, melainkan dunia itu sendiri punsejauh terkait dengan pikiran manusia-seluruhnya terdiri atas tanda-tanda karena, jika tidak begitu, manusia tidak akan bisa menjalin hubungannya dengan realitas. Bahasa itu sendiri merupakan sisten tanda yang paling fundamental bagi manusia, sedangkan tanda tanda nonverbal seperti gerakgerik, bentuk-bentuk pakaian, serta beraneka praktik sosial konvensional lainnya, dapat dipandang sebagai sejenis bahasa yang tersusun dari tandatanda bermakna yang dikomunikasikan berdasarkan relasi-relasi.

\section{Semiotika John Fiske}

Semiotika membantu untuk menafsirkan berbagai tanda komunikasi, baik tanda alam maupun tanda buatan, semiotika mampu untuk menafsirkan makna-makna baik yang tersirat maupun tersurat, karena pada dasarnya semiotika berdasarkan pada logika atau subjektivitas si penafsir itu sendiri, hal inilah yang memunculkan beberapa aliran semiotika, seperti aliran semiotika strukturalisme, pragmatism, post-modernisme dan pembedanya adalah subjektivitas yang berdasar pada epistimologis, ontologis, aksiologis dan metodologis. Tanda-tanda yang ada dalam semiotika biasanya terdiri atas tanda natural, yaitu tanda yang terjadi secara alami, dan tanda konvensional, yaitu tanda yang khusus dibuat untuk komunikasi.

Semiotika John Fiske mengikuti aliran poststrukturalisme, aliran ini lahir karena ketidaksetujuan terhadap aliran strukturalisme yang dipelopori oleh Ferdinand De Saussure yang mengatakan tanda dalam semiotika adalah sesuatu yang mengikat, dan tidak memberi 
kemungkinan akan terciptanya kreativitas tanda-tanda yang baru dan aliran poststrukturalisme menolak segala bentuk keterikatan dengan konvensi, aturan atau kode-kode baru, sebaliknya, ia membuka ruang bagi model-model bahasa dan pertandaaan yang kreatif, produktif, subversive, transformative, bahkan terkadang anarkis (Piliang, 2010:259).

\section{METODE PENELITIAN}

Menggunakan pendekatan kualitatif dengan metode analisis isi semiotika, penelitian ini ingin membongkar makna simbol atau bahasa verbal dan nonverbal dalam iklan Vitaglow fair \& lovely untuk mengetahui pemaknaan iklan tersebut dengan melihat beragam kecantikan perempuan tanpa melihat warna kulit, rambut, agama dan lain-lain pada iklan tersebut. Selain itu, penelitian ini juga ingin mengetahui makna realitas, makna representasi, dan makna ideologi dalam iklan Vitaglows fair \& lovely 2020.

Pendekatan penelitian ini menggunakan metode kualitatif diskriptif. Penelitian ini berusaha mengkaji scene dalam iklan Vitaglow Fair \& Lovely 2020 dengan mendeskripsikan atau mencari makna level realitas, level representasi, level ideologi menurut John Fiske.

Secara epistemologis, penggalian makna yang melibatkan perhatian pada sistem pertandaan merefleksikan pendekatan semiotik dalam analisis media. Pendekatan semiotika memandang komunikasi sebagai produksi dan pertukaran makna (productions and exchange of meaning). Pandangan ini memperhatikan bagaimana pesan berhubungan dengan penerimanya untuk memproduksi makna. Aliran semiotik memandang peran penguasaan makna kepada penerima pesan. Penerima pesan mempunyai otoritas mutlak untuk menentukan makna-makna yang ia terima dari pesan, sehingga peran source atau sender cenderung terabaikan.

\section{Objek Penelitian}

Objek kajian dalam penelitian ini adalah iklan Masker Vitaglow Fair \& Lovely. Identifikasi terhadap objek penelitian ini adalah tanda-tanda yang muncul dalam iklan tersebut yang merujuk pada makna level realitas, level representasi, level ideology. Iklan ini berdurasi 31 detik dan diputar di berbagai stasiun televisi swasta yang ada di Indonesia.

\section{Hasil Penelitian}

\section{Level Realitas}

Iklan menggunakan pengambilan gambar medium shoot dan close up, pada semua talent sesuai pada kajian teori. Iklan ini memfokuskan pada visual wajah yang bersih dan cerah 
serta tidak terlihat riasan yang tebal atau tampak natural. Pengambilan gambar yang berfokus pada wajah dan pakaian yang dipakai untuk merepresentasikan citra perempuan feminim pada iklan ini yaitu suka merawat diri baik itu wajah dan badan, selalu terlihat ceria baik gesture tubuh dan bicaranya.

Disini warna yang dominan ada dua yang pertama merah muda (pink) yang merepresentasikan citra perempuan itu sendiri dan juga mewakili produk karena produk tersebut berwarna merah muda (pink). Makna warna ini merepresentasikan prinsip feminim dan banyak disukai oleh para wanita, auranya yang kuat memberi benak kita nuansa kelemahlembutan, peduli, dan romansa. Warna lainnya yaitu warna putih di samping mewakili produk dan citra perempuan juga warna putih diartikan glowing bahwa semua perempuan yang cantik hampir memiliki kulit berwarna putih. Warna putih menggambarkan kesederhanaan, kemurnian, tidak bersalah dan kesempurnaan.

\section{Level Representasi}

Representasi yang muncul dalam video iklan tersebut bercahaya atau glowing, dimana realitas saat ini sudah dapat menampilkan perempuan-perempuan remaja yang cantik itu harus memiliki wajah yang bercahaya atau glowing. Teknik pengambilan gambar ini merupakan jenis shot medium close up untuk menunjukkan wajah objek agar lebih jelas dengan ukuran shot dari dada sampai puncak kepala. Pada video ini mereperesentasikan bahwa semua kalangan perempuan remaja baik itu yang berambut panjang, berambut pendek, feminim atau tidak, berhijab atau tidak semuanya menginginkan kulit wajah yang bercahaya atau glowing. Video ini juga menonjolkan karakter remaja perempuan yang penuh energi dan ceria yang merepresentasikan masa remaja yang penuh energi, rasa ingin tahu, pencarian identitas dan ekpresif.

\section{Level Ideologi}

Iklan ini menyuguhkan tiga karakter perempuan yang berbeda-beda lewat kode pakaian dengan memenuhi standar yang sama. Bagian pertama ini atau di talent perempuan yang pertama ini menunjukan ideologi feminitas yang benar-benar mempresentasikan pure perempuan yang ceria, fun, peduli merawat diri dan peduli akan sesama perempuan.

Di sisi lain, level ideologi konsumerisme dimana diperlihatkan para remaja ini membeli produk tersebut agar terlihat menarik karena mereka ingin dapat terlihat menarik baik itu di lingkunannya atau untuk pribadinya sendiri. Factor lingkungan mempengaruhi ideologi ini 
karena bila seseorang sudah memakai produk tersebut pasti akan mengajak oang lain untuk membeli serta sifat yang dimiliki untuk mencapai kepuasaan dirinya sendiri dengan mencontoh gaya penampilan orang lain.

Selain itu, level ideologi lainnya seperti video iklan dimana tiga perempuan talent terlihat bercahaya baik muka maupun latar. Pesan yang ditampilkan video ini menunjukan sebuah pesan kapitalisme dimana tiga perempuan talent telah memotivasi perempuan-perempuan untuk tidak merasa rendah diri dan berani berubah dalam penampilan mereka guna meraih keuntungan.

Analisis level ideologi pada iklan video Vitaglows Fair \& Lovely menggambarkan feminitas yang benar-benar mempresentasikan pure perempuan yang ceria, fun, peduli merawat diri dan peduli akan sesama perempuan. Ideologi konsumerisme iklan tsb merepresentasikan pesan kapitalisme dimana ketiga talent telah memotivasi perempuanperempuan untuk tidak merasa rendah diri dan berani berubah dalam penampilan mereka namun tetap menggiring impian untuk mengubah tampilan dan meraih keuntungan.

\section{E. SIMPULAN DAN SARAN}

Analisis level realitas menggambarkan bahwa musik yang ceria dan fun dalam iklan tsb mendeskripsikan membangkitkan semangat, kebahagiaan dan membuat sesuatu menjadi lebih tenang dan terang. Warna merah dan putih dalam iklan Vitaglows Fair \& Lovely mendeskripsikan warna ini merepresentasikan prinsip feminim dan banyak disukai oleh para wanita, auranya yang kuat memberi benak kita nuansa kelemahlembutan, peduli, dan romansa. Warna putih pada produk menggambarkan kesederhanaan, kemurnian, tidak bersalah dan kesempurnaan.

Analisis level representasi pada video iklan Vitaglows Fair \& Lovely mereperesentasikan bahwa semua kalangan perempuan remaja baik itu yang berambut panjang, berambut pendek, feminim atau tidak, berhijab atau tidak semuanya menginginkan kulit wajah yang bercahaya atau glowing.

Analisis level ideologi pada iklan menggambarkan feminitas yang mempresentasikan pure perempuan yang ceria, fun, peduli merawat diri dan peduli akan sesama perempuan. Ideologi konsumerisme iklan tsb merepresentasikan pesan kapitalisme dimana ketiga talent perempuan telah memotivasi perempuan lain untuk tidak merasa rendah diri dan berani berubah dalam penampilan mereka namun tetap menggiring impian untuk mengubah tampilan dan meraih keuntungan. 
Saran yang akan disampaikan yaitu :

1. Segala bentuk isi iklan yang ditujukan ke masyarakat harus menjadi tanggung jawab penuh dari media. Media menampilkan isi iklan harus proporsional dan kembali ke fungsinya bahwa media memberikan informasi yang benar kepada masyarakat.

2. Masyarakat terutama perempuan harus mampu menyaring informasi atau pesan dari iklan yang ditayangkan dan tidak mudah percaya terhadap isi iklan tersebut

\section{Referensi}

John Fiske, Pengantar Ilmu Komunikasi Edisi Ketiga

Muhammad Jaiz, Dasar-Dasar Periklanan, (Yogyakarta: Graha Ilmu, 2014),

Marcel Danesi, Pengantar Memahami Semiotika Media, Jalasutra Yogyakarta, 2010, Alex Sobur, Analisis Teks Mesia : Suatu Pengantar. (Bandung: Remaja Rosdakarya,2006) Arthur Asa Berger, Pengantar Semiotika: Tanda-tanda dalam Kebudayaan

Kontemporer (Yogyakarta: Tiara Wacana, 2010).

Alex Sobur, Semiotika Komunikasi (Cet. III; Bandung: PT. Remaja Rosdakarya, 2006)

Hendy Y, Belajar Membuat Iklan Sukses (Yogyakarta: Graha Ilmu, 2009)

Morissan, Periklanan: Komunikasi Pemasaran Terpadu (Jakarta: Kencana, 2010)

Marcel Danesi, Understanding Media Semiotics, Diterjemahkan oleh A. Gunawan Admiranto dengan Judul Pengantar Memahami Semiotika Media (Cet. I; Yogyakarta: Jalasutra, 2010)

Muhammad Jaiz, Dasar-Dasar Periklanan, (Yogyakarta: Graha Ilmu, 2014),

Kamus Besar Bahasa Indonesia, "Representasi" https://www.kbbi.web.id/representasi diakses pada 20 Januari 2018 pukul 12.15 WIB

Marcel Danesi, Pengantar Memahami Semiotika Media, (Yogyakarta: Jalasutra, 2004) Ratna Noviani. 2001. Jalan tengah memahami iklan. Sembiosa Prenada Media. Jakarta Semiotika "analisis praktis bagi penelitian dan penulisan skripsi ilmu komunikasi" Oleh Drs. Indiwan Seto Wahyu Wibowo, M.Si. 2006

Analisis Semiotika Roland Barthes Makna Pada Iklan Sprite Edisi Kenyataan Gak Sebombastis Film Aksi oleh Robi Mubarok. (Skripsi, UIN Sunan Ampel, Surabaya)

Representasi Kesabaran Muslimah Dalam Iklan Sunsilk Clean And Fresh Versi Risty Tagor oleh Evita Nanda Karunia (Skripsi, 20017)

Analisis Semiotika Dalam Iklan Shopee 12.12 Birthday Sale Edisi Blackpink Oleh Adinda Rita Dara. Jurnal sosiologi USK Volume 13. Nomor 2 Desember 2019

Citra Tubuh Positif Dalam Iklan Video Digital (Study Femvertising Pada Iklan Dove Real Beauty) oleh Nur Kumalaningtyas, Lidwina Mutia Sadasri (Skripsi, 2018)

Simbolis Dan Pemaknaan Iklan Susu Bear Brand Edisi 2015 oleh Mia Mufidah. (Skripsi, UIN

Alauddin, Makassar)

Bakti, Indra Setia; Nirzalin, Alwi. Konsumerisme dalam Perspektif Jean Baudrillard. Jurnal Sosiologi Universitas Syiah Kuala Volume 13 No 2 Desember 2019. Universitas Syah Kuala.

Nirzalin. 2013. Mendamaikan Aktor dan Struktur dalam Analisis Sosial Perspektif Teori Strukturasi Antony Giddens. Jurnal Sosiologi Universitas Syiah Kuala 3(3): 15-23 
JIKE: Jurnal Ilmu Komunikasi Efek

p-ISSN 2614-0829 